\title{
Medios digitales y funcionalismo: reflexiones del estreno de Joker
}

\author{
Erick Daniel Cruz-Mendoza* \\ Recibido: 2020-07-02 • Enviado a pares: 2020-07-20 \\ Aprobado por pares: 2020-08-05 • Aceptado: 2020-08-25 \\ https://doi.org/10.22395/angr.v19n38a9
}

\begin{abstract}
Resumen
Joker es una cinta que obtuvo relevancia por dos aspectos: los halagos de la crítica luego de su presentación en el Festival de Cine de Venecia (28 de agosto al 7 de septiembre de 2019) al recibir el máximo galardón del evento, León de Oro, y por la polémica generada previo a su estreno al público. En ese sentido, el propósito de este trabajo es identificar las relaciones cualitativas entre el estreno de la cinta Joker y la histeria colectiva expresada en las redes sociodigitales a partir de los postulados del sociofuncionalismo en comunicación. Este fenómeno adquiere sentido a partir de las noticias presentadas por los medios informativos previo al estreno de la cinta y a la respuesta del público, el cual se mostró polarizado. Se recurre al análisis de una muestra no probabilística como evidencias para atender la insuficiencia de las analogías funcionalistas en su intento por retratar fenómenos que se vinculan directamente con las lógicas de los nuevos medios digitales.
\end{abstract}

Palabras clave: funcionalismo; comunicación de masas; comunicación digital; cine (medios); investigación sobre la comunicación; sociología de la comunicación; impacto de la comunicación; medios de comunicación de masas.

Artículo de investigación asociado a la maestría en Comunicación y Cultura Digital, Facultad de Ciencias Políticas y Sociales, Universidad Autónoma de Querétaro, México. Esta investigación se llevó a cabo de octubre a diciembre de 2019.

* Estudiante de la maestría en Comunicación y Cultura Digital, Facultad de Ciencias Políticas y Sociales, Universidad de Querétaro, Querétaro, México. Correo electrónico: ecruz44@alumnos.uaq.mx. Orcid: https://orcid.org/0000-0001-9632-2319 


\title{
Digital Media and Functionalism: Reflections from the Joker Premiere
}

\begin{abstract}
Joker is a film that gained relevance for two aspects: the praise of the critics after its presentation at the Venice Film Festival (August 28 to September 7, 2019) when it received the highest award of the event, Golden Lion, and due to the controversy generated prior to its premiere to the public. In this sense, the purpose of this work is to identify the qualitative relationships between the premiere of the Joker film and the collective hysteria expressed in socio-digital networks, based on the postulates of social-functionalism in communication. This phenomenon acquires meaning from the news presented by the media prior to the premiere of the film and the response of the public, which was polarized. The analysis of a non-probabilistic sample is used as evidence to address the insufficiency of functionalist analogies in their attempt to portray phenomena that are directly linked to the logic of the new digital media.
\end{abstract}

Keywords: functionalism; mass communication; digital communication; cinema (media); research on communication; sociology of communication; impact of communication; mass media 


\section{Introducción}

Este trabajo de reflexión parte de la siguiente pregunta: ¿Existen relaciones cualitativas entre el clima de violencia expuesto en el entorno digital previo al estreno de Joker? Para responder esta cuestión, se ponen en discusión algunos acontecimientos que se efectuaron en las redes sociodigitales, principalmente en Facebook y Twitter. Lo anterior tiene la intención de exponer las interacciones que ocurren en estas redes, las cuales contribuyen a explicar un modelo de flujo informativo funcionalista que, si bien sirve como punto de partida para entender la histeria social, es insuficiente para estudiar fenómenos comunicativos situados en el nivel de los nuevos medios digitales (Jensen, 2014).

En primer lugar, se revisan las reflexiones de Lasswell (1948) en su intento por explicar la relación de los medios con las audiencias. También se ahonda en las vastas conversaciones sobre las teorías de la comunicación con especial énfasis en las aportaciones de la sociología funcionalista (Vidales, 2014; García, 2015) con el objetivo de brindar al lector un panorama amplio de esta perspectiva.

En este sentido, se describe la teoría de la aguja hipodérmica para comprender su importancia en la investigación de los medios de difusión en el periodo de los años veinte y treinta del siglo XX en Estados Unidos (Pineda, 2007). Estas explicaciones sientan las bases para brindar una explicación funcionalista del flujo informativo ocurrido previamente al estreno de Joker. Además, se profundiza en el análisis del entorno digital a partir de las noticias relevantes que dieron origen al debate de la cinta y su relación con la violencia que puede ocasionar su estreno. Al final, se pone en discusión el estudio de los medios digitales y las redes sociodigitales a partir de los postulados de la sociología funcionalista de la comunicación.

\section{La comunicación y la sociología funcionalista}

Para Galindo (2007), la historia del funcionalismo en comunicación se asocia sin razón al auge de los estudios empíricos de la propaganda acontecidos durante los años veinte del siglo pasado en Estados Unidos. Esta es una vaguedad, ya que la corriente tuvo su auge en dicho país, pero fue durante los años cuarenta a sesenta. Según el autor, esto se debe a una serie de imprecisiones entre sociología empírica y sociología teórica que han llevado a los estudiosos en comunicación a homologar la producción en ciencias sociales de corte estadounidense como funcionalista en su totalidad. De ahí que los estudios empíricos sobre propaganda desarrollados por Harold Lasswell (1927) en la Universidad de Chicago sean considerados, por su relación con los medios de difusión masiva, como los inaugurales de la corriente funcionalista en comunicación. En realidad, dicha génesis alude a la publicación de Propaganda techniques in the world war de Lasswell (1927, citado en Cuesta y Gaspar, 2013). 
En la sociología empirista de Lasswell destaca el conductismo psicológico y el funcionalismo como bases para comprender la persuasión promovida por los medios a través de sus mensajes. Por un lado, el conductismo se cristaliza en la idea de estímulo-respuesta o causa-efecto generados en el humano a partir de su relación con el ambiente. Por otro lado, en el funcionalismo se recupera la analogía de la sociedad como organismo vivo que funciona a partir de los diferentes componentes que la integran, entre ellos están los medios de difusión (Sosa y Arcila, 2013). Dichas influencias teóricas se reflejan en las obras de Lasswell (1948) (estudios en medios de difusión) y posteriormente en la de Lazarsfeld y Merton (1985) (sociología funcionalista). Estos últimos son autores clave de mass communication research. En este contexto, afirma Galindo (2007):

La diferencia sustantiva entre los estudios en medios de difusión masiva y la sociología funcionalista fue precisamente que unos estaban interesados en los datos y perfiles empíricos de los públicos y audiencias, y la otra en la construcción de una gran teoría abstracta de la sociedad. El contacto es sutil, más por ambiente social-político y en parte académico que por programa de trabajo científico. La afirmación de que poco o nada tuvieron en común es más una primera hipótesis de trabajo que una conclusión definitiva. Si por una parte parece que la relación evidente fue insustancial, por otra parte, ante la no evidencia habría que hilar más delgado. (p. 171)

En cuanto al protagonismo de los autores en el campo de la comunicación, se suele recurrir a Lasswell, Lazarsfeld, Lewin y Hovland -y después a Wilbur Schramm - cuando se habla de los fundadores (Fuentes-Navarro y Vidales-Gonzáles, 2011). Lo anterior es un indicador de la importancia del funcionalismo en los estudios empíricos de dicho campo. Esto no quiere decir que el campo se constituyó a partir de la presentación del trabajo de Lasswell, ya que el núcleo académico de la comunicación fue inaugurado formalmente en los Estados Unidos en el año de 1937 con la aparición de la revista de la Universidad de Oxford: The public opinion quarterly (Galindo, 2007).

En esta primera fase de los estudios de comunicación, que aconteció durante los años veinte y treinta, predominó el análisis de los efectos de los medios de masas sobre las audiencias (Álvarez-Gálvez, 2012). Este hecho fue influenciado, en parte, por el desarrollo de la propaganda en la Primera Guerra Mundial que mostraba a las audiencias como pasivas ante los todopoderosos medios de difusión. En este sentido, afirma Álvarez-Gálvez (2012): "de ahí que se pensara que los medios de comunicación de masas producían efectos instantáneos y masivos sobre la audiencia" (p. 2). 
A continuación, se ilustran los principales postulados de Lasswell, Lazarsfeld y Merton en el marco del funcionalismo en comunicación (figura 1).

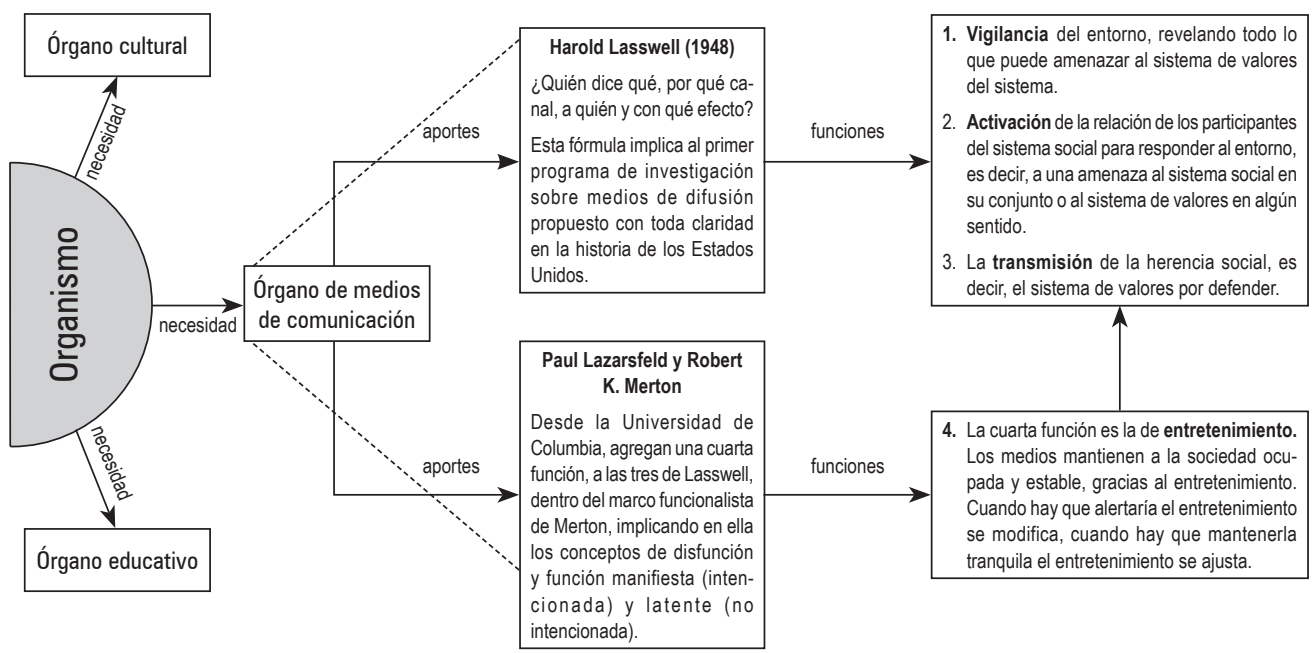

Figura 1. Funcionalismo en comunicación

Fuente: elaboración propia con información de Galindo (2007) y Cadenas (2016).

De esta forma, las ideas del politólogo Lasswell reflejaban el espíritu mecanicista de la época (Demirdjian, 2011) que estaba impulsado por la idea de los medios como órganos indispensables para la difusión de propaganda estadista para dirigir la opinión de las audiencias con base en el modelo de los efectos instantáneos provocados por el estímulo-respuesta. Pese a la hegemonía norteamericana que caracteriza la segunda mitad del siglo XX (Román, 2002), las teorías funcionalistas fueron desplazadas por la corriente crítica de la escuela de Frankfurt y encontraron un lugar de resguardo en las teorías de los efectos limitados y en los estudios de la propaganda (Requeijo, Sanz y Del Valle, 2013; Vázquez y Leetoy, 2016).

\section{Bala mágica, aguja hipodérmica o transmisión en cadena}

La principal aportación de Lasswell, por la cual se considera como padre fundador de las ciencias de la comunicación, es la teoría de la bala mágica. Lasswell (1927) desarrolla en su estudio clásico Propaganda techniques in the world war. En este estudio, se hace referencia a la capacidad de persuasión de los medios para que su mensaje apunte a un objetivo, algo similar a lo propuesto por Wiener en su proyecto de la cibernética desarrollado en la posguerra (Castaños, 2000).

Para Hernández-Santaolalla (2018), la bala mágica es resultado del clima de temor latente en las audiencias estadounidenses ocasionado por los medios de comunicación de masas durante la Primera Guerra Mundial. Esta visión optimista 
que concibe a los medios como instrumentos poderosos para la propaganda recibió posteriormente el nombre de aguja hipodérmica y el de transmisión en cadena. Al respecto, Álvarez-Gálvez (2012) citan a D’Adamo, García Beaudoux y Freidenberg para aclarar que "en cualquier caso [...] la analogía, tanto con la aguja hipodérmica como con la bala, sirve para ilustrar de manera gráfica el efecto directo y rápido que se postulaba que los mensajes proyectados a la audiencia producían" (p. 3).

De lo anterior se observa la presencia de las premisas del conductismo y el funcionalismo en la postura de Lasswell, quien se aventura a formular la teoría de la aguja hipodérmica (Ramos, 2014), caracterizada por su visión de omnipresencia y omnipotencia de los medios. En este sentido, afirma Hernández-Santaolalla (2018):

Las nuevas teorías sobre la sociedad de masas señalaron el punto de partida y los profesionales de la propaganda siguieron el camino. Las ideas de Herbert Spencer, Auguste Comte, Ferdinand Tönnies o Émile Durkheim presentaban un nuevo tipo de sociedad, un modelo formado por individuos más independientes y heterogéneos, regidos, no obstante, por una serie de normas comunes. (p. 74)

En términos ilustrativos, la aguja hipodérmica se asocia con la imagen de los medios. De esta manera, inyecta información en la sociedad de masas, destruye los vínculos primarios de los individuos y facilita la persuasión colectiva, todo eso basado en el conductismo clásico (Fernández, 2010). De ahí la ilustración de una aguja (medio) que alberga un líquido (mensaje) para ser suministrado en el tejido muscular (sociedad) (figura 2).

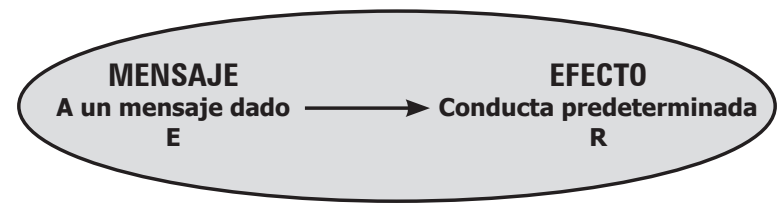

Figura 2. Elementos de la teoría de la aguja hipodérmica Fuente: Sosa y Arcila (2013, p. 28).

El clímax de esta teoría aconteció el 30 de octubre de 1938 en Estados Unidos, cuando Orson Wells protagonizó el drama radiofónico La guerra de dos mundos. Boni (2008) explica que esta emisión es famosa porque desencadenó el pánico entre los radioescuchas, quienes salieron a las calles escandalizados por la invasión marciana o, por lo menos, es lo que se contó durante años hasta que un estudio realizado por Cantril (1942) contribuyó a dimensionar el impacto de dicha emisión.

Para no perder de vista el sentido de estos postulados, es necesario contextualizarlos en el periodo entreguerras, en donde la propaganda bélica fungió como 
protagonista de los estudios de efectos y de opinión. De esta manera, se entiende que la reacción ante los mensajes no fue con un sentido crítico o de resistencia, sino que, a pesar de la capacidad de los medios para instaurar contenidos, no se ha demostrado empíricamente que el receptor actúe de acuerdo con las pautas estipuladas por los emisores (Do Campo, 2015). Esta premisa considera las masas como un grupo manipulable sin pensamiento propio (Com, Ackerman y Morel, 2011). Pero se viene abajo con la llegada de los estudios críticos de la escuela de Frankfurt y su influencia en Gerbner y Gross (Universidad de Pennsylvania 1960-1970), quienes complejizan la manipulación de los productores de los mensajes y los efectos de estos a partir de la teoría del cultivo.

Como se ha expuesto, la introducción de la sociología funcionalista en comunicación tuvo lugar en los años veinte en Estados Unidos, su clímax en los treinta y posteriormente su punto de tensión vino a la baja con el desarrollo de otras reflexiones más críticas frente a los todopoderosos medios de difusión. En los años consecutivos surgieron otras teorías que contrastan con estas, como lo fue la teoría crítica de la escuela de Frankfurt mediante los usos y las gratificaciones, la teoría de los dos pasos, la teoría del comportamiento social, la agenda setting, la espiral del silencio, la teoría del cultivo, entre otras.

La anterior descripción es útil para ilustrar los procesos de ruptura entre las teorías de la comunicación sin profundizar en cómo se dieron —o se están dandoestos, pues el propósito principal es traer a la luz los postulados funcionalistas para reflexionar un fenómeno de la cultura digital.

\section{Joker}

Primero, es necesario definir que el fenómeno a explorar se encuentra inmerso en el entorno digital. Este fenómeno es resultado de la convergencia entre sociedad y tecnología en el marco de la sociedad de la información, en donde el desarrollo de esta ha dado lugar a un nuevo ámbito de la realidad compartida de dicha sociedad (Barroso, 2013). De ese ámbito compartido, que ha sido posible gracias a las tecnologías de la información y comunicación (TIC) y el internet, se tomará únicamente el frame de la World Wide Web.

En este trabajo se ensayan los postulados de Lasswell, en específico lo relacionado con la bala mágica, para explicar desde estos lo que he denominado el fenómeno Joker. Joker es un filme dirigido por Todd Phillips (2019), se estrenó a nivel internacional el 4 de octubre de 2019 y fue glorificado previamente por su presentación en el Festival de Cine de Venecia, en donde fue condecorada con el León de 
Oro. El filme tiene como protagonista a Joaquin Phoenix, quien desarrolla la historia de origen del principal villano de Batman.

"Joker" se centra en el icónico archienemigo y es una historia ficticia original e independiente que no se había visto antes en la pantalla grande. La exploración de Phillips de Arthur Fleck, quien es retratado indeleblemente por Joaquin Phoenix, es sobre un hombre que lucha por encontrar su camino en la sociedad fracturada de Gotham. Payaso de alquiler de día, aspira a ser un cómico de pie por la noche ... pero descubre que la broma siempre parece estar en él. Atrapado en una existencia cíclica entre la apatía y la crueldad, Arthur toma una mala decisión que provoca una reacción en cadena de eventos cada vez. (Rotten Tomatoes, 2019, traducción propia) ${ }^{1}$

Joker es una cinta de clasificación internacional R (restringido) debido al contenido de escenas violentas o lenguaje agresivo. En México la clasificación que se le otorga es la B-15, lo que permite la entrada de menores de edad únicamente acompañados de un adulto. El "fenómeno Joker" al que se hace referencia no es como tal la cinta, es decir, no es el análisis cinematográfico del contenido en sí, sino que se discute lo previo a su presentación en las salas de cine públicas.

El punto de partida se encuentra en la relación cualitativa de la cinta con la violencia que puede generarse en el estreno. A esto se suman los comentarios difundidos en las redes sociodigitales en donde se solicita el apoyo de la milicia estadounidense en el estreno del Joker. Para esta solicitud, se argumenta la réplica de los acontecimientos ocurridos el 20 de julio de 2012 en Aurora, Denver (Colorado) en la presentación de The dark knight rises (Nolan, 2012), en donde un hombre de veintitrés años utilizó el apagón de luces para lanzar gas lacrimógeno y disparar al interior de la sala, en la que mató a doce personas. En este sentido, afirma Ximénez de Sandoval (2019):

El asesino, además, tenía el pelo teñido de rojo fosforito y cara de alucinado. El rumor de que cometió la masacre porque estaba convencido de que era el Joker forma parte de la cultura conspirativa de internet. El fiscal del caso niega que fuera así. Un psicólogo que lo trató también lo niega. Y, sin embargo, no hay forma de hacer desaparecer la teoría de que el desquiciado que cometió la masacre de Aurora estaba obsesionado con ese personaje. Todos estos antecedentes forman el contexto del estreno de la película de Phillips. (p. 3)

En el original: "'Joker' centers around the iconic arch nemesis and is an original, standalone fictional story not seen before on the big screen. Phillips' exploration of Arthur Fleck, who is indelibly portrayed by Joaquin Phoenix, is of a man struggling to find his way in Gotham's fracturedsociety. A clown for hire by day, he aspires to be a stand-up comic at night...but finds the joke always seems to be on him. Caught in a cyclical existence between apathy and cruelty, Arthur makes one bad decision that brings about a chain reaction of escalating events in this gritty character study" (Rotten Tomatoes, 2019). 
A decir de esta imagen generada en torno a las películas en las que aparece el Joker, la de Phillips (2019) despertó el interés público previamente debido a la crítica y a las reacciones del Ejército de Estados Unidos y la Policía de Los Ángeles. A finales de agosto circuló en Facebook una amenaza de tiroteo planeada para el estreno de la cinta en los Estados Unidos. El contenido se hizo viral al grado de que los familiares de las víctimas del atentado de Aurora enviaron una carta abierta a Warner en donde se apelaban a su influencia para presionar al Congreso en la reforma de utilización de armas. Por su parte, Warner respondió que el personaje ni la cinta son apologías de la violencia y reconoció públicamente su apoyo a las víctimas de Aurora. Luego de esto, el Ejército de Estados Unidos y la Policía de Los Ángeles expresaron que se mantendrán alerta durante la proyección de la película (Garvey y Starr, 2019).

\section{Metodología}

Para ahondar en el terreno de Joker, se realizó en Alexa (Amazon) una búsqueda (el 4 de octubre de 2019) de tipo contenido (identifica el contenido más exitoso para un tema) basada en los tuits. De esta manera, se tomó como criterio el orden por sentimiento social (me gusta + retuits - respuestas). Cabe señalar que esta acción es efectuada por el software, por lo que no existe intervención del investigador para diferenciar los términos positivos, negativos y neutrales. Para este ejercicio se consideró una muestra no probabilística de tipo teórica que ayudara a conocer la relevancia de los contenidos que utilizan la palabra Joker a partir del criterio de sentimiento social. A continuación, se exponen siete ejemplos seleccionados de la lista de los primeros veinte contenidos que el buscador arrojó con las claves antes mencionadas.

Aparecen únicamente los contenidos relacionados con la violencia para evidenciar el posicionamiento de estos en la web a partir de las métricas ofrecidas por Twitter. Se eligieron los primeros siete titulares de una lista de cien, entre los cuales se repetía constantemente el mismo mensaje, por lo que se recurrió al criterio de saturación o redundancia informativa (González y Orozco, 2012).

El propósito de este corpus es contextualizar la discusión acerca de la influencia de los contenidos producidos por los medios masivos, en este caso por el cine. Esto se hizo con la intención de discutir dicho fenómeno desde el funcionalismo comunicacional. Cabe aclarar que esta interpretación no justifica los actos de los usuarios ni de los demás actores involucrados, sino que el fin es exponer el escenario sobre el cual se teje un fenómeno desde el punto de vista de la comunicación y la cultura digital. 


\section{Resultados}

Luego de realizar una búsqueda del contenido vinculado con Joker en el software Alexa (Amazon), estos son los titulares de las noticias que expresan en términos semánticos una relación entre la violencia y la cinta o el personaje (tabla 1):

Tabla 1. Ejercicio de contenido en el programa Alexa (Amazon) con la palabra "Joker"

1 Review: 'Joker' is a dangerous film that will incite lonely white men to try stand-up comedy.

2 Joker movie gets an official Hard R rating.

3 Joker rated R for "strong bloody violence, disturbing behavior".

4 Todd Phillips explains why he left comedies for 'Joker': "go try to be funny nowadays with this woke culture".

5 Select Joker screenings to be policed with nypd undercover tactics for opening weekend.

6 U.S. military issues warning to troops about incel violence at Joker screenings.

7 Everyone in Joker audience waiting for right moment to do mass shooting.

Fuente: elaboración propia con información del programa Alexa (Amazon).

Como se observa, a la par de los elogios a esta película, se generó un ambiente de tensión conexo con la violencia. De aquí surge la siguiente cuestión: ¿Existen relaciones cualitativas entre Joker y el clima de violencia expuesto en el entorno digital previo a su estreno? En primer lugar, hay que decir que los usuarios de Facebook viralizaron la información sobre las amenazas de tiroteos en los cines, lo cual llevó al Ejército de Estados Unidos y a la Policía de Los Ángeles a investigar esta información. Inmediatamente, las familias de las víctimas del atentado de Aurora se pronunciaron hacia Warner con el fin de solicitar apoyo para erradicar la violencia. La empresa respondió negando que la producción de esta cinta estimula a cometer actos de ese tipo.

La tabla evidencia la dirección de las noticias previo al estreno de la cinta. Sin embargo, a partir de esta no se puede establecer una correlación directa entre la violencia contextual y una producción cinematográfica. Por ello, su función es estratégica y su sentido es ubicar la situación en donde los medios de comunicación contribuyen a acrecentar el halo de un estreno. Dicho de otro modo, no hay una relación entre la producción de noticias y una posible ola de violencia, ya que es imposible prever eso. No obstante, en términos cualitativos se pueden establecer varias relaciones para debatir, desde una mirada funcionalista, por qué hay sujetos que consideran al Joker como un detonante del terror que rebasa las paredes de las salas de cine. 


\section{Discusión y conclusiones}

En el primer apartado se dijo que la sociología funcionalista en comunicación y en específico la teoría de la aguja hipodérmica perdió relevancia académica al no poder constatar sus postulados conductistas sobre el poder de los medios de difusión para causar un efecto inmediato en las audiencias. Sin embargo, esta tuvo su clímax con la presentación de La guerra de dos mundos en 1938 una emisión que generó pánico en los radioescuchas al grado de sacarlos de sus hogares para huir de la invasión extraterrestre. Ante esto, se exige una reflexión contextualizada, en donde se comprende el papel de los medios de difusión en el periodo de las guerras mundiales y cómo estos contribuyeron a formar una visión apocalíptica de lo acontecido.

Al tomar en cuenta esto, con Joker no se espera que los cinéfilos actúen violentamente al ver la cinta, es decir, no se piensa en una relación instantánea de causa y efecto, como se ilustra en la analogía de la aguja hipodérmica y la bala mágica. Aunado a ello, la interacción que se genera en las redes sociodigitales se encuentra más allá de las explicaciones que ofrecen los postulados funcionalistas centrados en la comunicación de uno a uno y de uno a muchos, dado que ahora esta se amplifica y sucede de manera masiva de muchos a muchos (Jensen, 2014). En este contexto, el flujo informativo se desdibuja entre lo vertical y lo horizontal al grado de que los receptores o públicos también influyen en las repuestas de las organizaciones de medios y otras industrias inmersas en el intercambio de mensajes.

Además, otros factores se suman a este tipo de fenómenos comunicativos, como lo es la ubicuidad (Jensen, 2014), de la cual gozan los usuarios para emitir sus comentarios sin repercusiones directas gracias a las estrategias de anonimato características de las redes sociodigitales. Este hecho sucedió con la viralización de la violencia (Soto et al., 2017) a través de la amenaza de tiroteo en el estreno de la cinta en Los Ángeles, California, la cual fue posteada en un blog desde la ciudad de Córdoba, Argentina.

En ese escenario, las familias de las víctimas de Aurora, al conocer las amenazas, se manifestaron inmediatamente y apelaron a la participación de la milicia norteamericana en la seguridad de los recintos en donde se tenía planeado el estreno de la cinta. Ahora bien, este hecho adquiere valor a partir de una reflexión contextualizada de Estados Unidos, en donde la violencia en espacios públicos ha estado latente en la última década. Solo por mencionar, desde el año 2012 se han cometido dos mil doscientos veinte tiroteos masivos en dicha nación (BBC News Mundo, 2019). En suma, otras cifras señalan que del 2000 al 2018 ocurrieron doscientos veinte tiroteos en instituciones de educación primaria y secundaria en 
Estados Unidos, en los cuales han estado expuestos más de doscientos dieciocho mil estudiantes (figura 3).

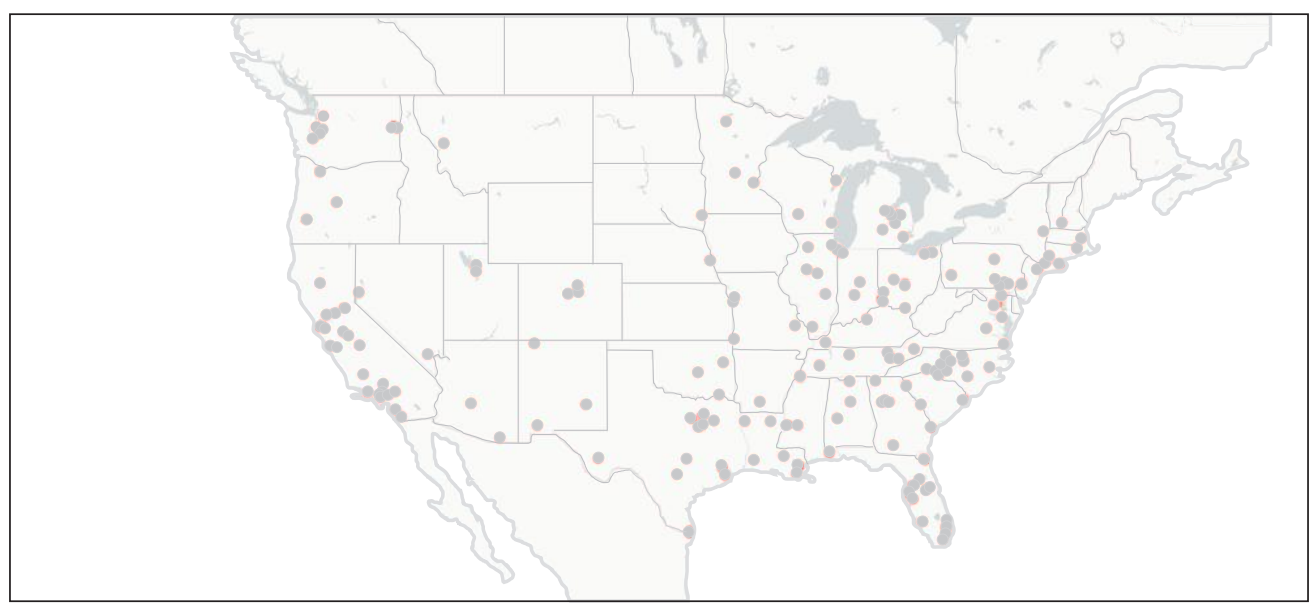

Figura 3. Mapa interactivo de los atentados en instituciones educativas de primaria y secundaria en Estados Unidos 2000-2018

Fuente: Hierro (2018).

Aunado a esto, se añaden los tiroteos de Texas y Ohio ocurridos el 3 y 4 de agosto de 2019, ambos relacionados con el racismo, en donde se registraron treinta y dos muertos y más de cincuenta heridos. ¿Cómo no alarmarse ante estas cifras si circulan contenidos con presencia de la violencia? De ahí que se recalque lo que afirma Lasswell (1948) en donde no se deben idealizarse como inmediatos al consumo de contenidos, pues, como se observa, en el entorno digital los prosumidores intervienen. De esta manera, se lleva esta discusión del mundo digital al analógico al estimular la movilización, como sucedió con la postura del ejército frente al "fenómeno Joker".

Este tipo de discusiones centradas en los flujos informativos, las interacciones de los usuarios y prosumidores y la viralización de la violencia en el escenario digital, buscan un lugar en el campo de la comunicación y la cultura digital porque ponen a prueba la actualidad de las explicaciones relacionadas con los efectos de los medios, las cuales fueron trazadas hace un siglo en Norteamérica. Sin duda, reconocer la actualización de estas para explicar fenómenos actuales implica un compromiso del investigador por conocer el pasado de su campo de producción. Por esa razón, son varios los trabajos que se publican hoy en día que buscan actualizar las teorías clásicas de la comunicación (Meneses y Pérez, 2016; Martín-Serrano, 2019). Lo anterior no representa una fobia a lo nuevo. Al contrario, lo que se busca es construir 
explicaciones para comprender que, si la realidad se transforma, también lo deben de hacer las teorías.

De esta manera, si se piensa en retrospectiva, La guerra de dos mundos (Haskin 1953) y Joker (Phillips, 2019) han producido diversas reacciones en los públicos. En el primer caso, las personas entraron en contacto con el contenido para reaccionar después. En el segundo caso, los públicos ni siquiera habían visto la cinta. Sin embargo, lo que se dice sobre esta en las redes sociodigitales y los antecedentes de violencia en los cines (Denver en 2012) son razones suficientes para profetizar sobre lo que puede ocurrir en su estreno. Lo anterior debe contextualizarse en un ambiente en el que la violencia va in crescendo y se relaciona con los espacios públicos, por ejemplo, las escuelas y los centros comerciales. Estos últimos lugares son estratégicos para comprender las acciones emprendidas por los afectados que han dejado los atentados previos.

En el cierre de este trabajo surge la siguiente pregunta: ¿Es pertinente seguir hablando de la aguja hipodérmica, bala mágica o transmisión en cadena en los tiempos del internet y las redes sociodigitales? Considerando la argumentación de los apartados precedentes, se puede expresar que The dark knight rises (Nolan, 2012) y Joker (Phillips, 2019) no son La guerra de dos mundos (Haskin 1953) del siglo XXI, pues el modelo de estímulo-respuesta es escueto para explicar la complejidad de este tipo de fenómenos comunicacionales en los entornos digitales. Cabe aclarar que con este enunciado no se está escribiendo el epitafio de los postulados que llevaron a Lasswell al podio de los padres fundadores de la comunicación. Al contrario, se invita a prestar atención a las explicaciones tradicionales para actualizarlas o generar nuevas reflexiones que avancen la discusión de las teorías de la comunicación y la cultura digital.

En ese sentido, es oportuno recordar las palabras de Galindo (2007), quien menciona que en el medio latinoamericano se ha vuelto una tradición nombrar al funcionalismo como al demonio. Para dicho autor, cuando esta crítica se vincula con la imagen de la aguja hipodérmica y esta última se retoma literalmente para decir que los medios tienen la capacidad de incidir en las actitudes de manera directa, la afirmación se convierte en el centro de burlas y ataques. Sin duda, dichas burlas deben superarse para convertirse en anécdotas que contribuyan a explicar el lugar de las teorías en la historia del conocimiento.

\section{Referencias}

Álvarez-Gálvez, J. (2012). Modelos teóricos sobre los efectos de los medios de comunicación de masas. Documentos de Trabajo, 2, 1-17. https://eprints.ucm.es/45089/1/doc\%20trab\%202.pdf 
Barroso, C. (2013). Sociedad del conocimiento y entorno digital teoría de la educación. Educación y Cultura en la Sociedad de la Información, 14(3), 61-86. https://www.redalyc.org/ pdf/2010/201029582004.pdf

BBC News Mundo (2019, 1 de octubre). "Joker": por qué genera tanta polémica la violencia que se muestra en la película sobre el villano de Batman. BBC. https://www.bbc.com/mundo/noticias-49894073

Boni, F. (2008). Teorías de los medios de comunicación (vol. 21) (trad. Julia Climent). Universidad Autónoma de Barcelona.

Cadenas, H. (2016). La función del funcionalismo: una exploración conceptual. Sociologías, 18(41), 196-214. http://www.scielo.br/pdf/soc/v18n41/1517-4522-soc-18-41-00196.pdf

Cantril, H. (1942). La invasión desde Marte.Estudio de la psicología del pánico. Revista de Occidente

Castaños, E. (2000). Los orígenes del arte cibernético en España. El seminario de Generación Automática de Formas Plásticas del Centro de Cálculo de la Universidad de Madrid (1968-1973) Itesis de doctorado, Universidad de Málaga]. Repositorio Universidad de Málaga. http://www. cervantesvirtual.com/obra/los-origenes-del-arte-cibernetico-en-espana-el-seminariode-generacion-automatica-de-formas-plasticas-del-centro-de-calculo-de-la-universidadde-madrid-19681973-0/

Com, S., Ackerman, S. y Morel, M. (2011). Introducción a la comunicación. Ediciones del Aula Taller.

Cuesta, U. y Gaspar, S. (2013). La I Guerra Mundial y los orígenes de la Teoría de los Efectos. El caso de aliadófilos y germanófilos. Historia y Comunicación Social, 18, 125 138. https://doi. org/10.5209/rev_HICS.2013.v18.43418

Demirdjian, L. (2011). Una mirada a los clásicos. La Escuela de Columbia, los efectos de los medios y su impacto en los actuales estudios de opinión. Comunicación y Sociedad, (16), 185-200. http://www.scielo.org.mx/scielo.php?script=sci_arttextEpid=S0188-252X2011000200008

Do Campo, D. (2015). Corrientes de la comunicación de masas I. La teoría hipodérmica. Grupo Interamericano de Reflexión Científica, 3, 1-9. http://www.reflexioncientifica.com.ar/15_GIRC_040.pdf

Fernández, M. (2010). Tradición y estudios actuales de sociología de la comunicación. Barataria, Revista Castellano Manchega de Ciencias Sociales, (11), 139-157. https://www.redalyc.org/ pdf/3221/322127621008.pdf

Fuentes-Navarro, R. y Vidales-Gonzáles, C. (2011). Fundaciones y fundamentos del estudio de la comunicación. Iteso. https://rei.iteso.mx/bitstream/handle/11117/2675/5862.pdf?sequence=2

Galindo, J. (2007). Sociología funcionalista y comunicología. El diálogo imposible en América Latina. Anagramas, 6(11), 161 182. https://revistas.udem.edu.co/index.php/anagramas/ article/view/749

García, J.A. (2015). Comunicar en la sociedad de la red. Teorías, modelos y prácticas. Barcelona, Editorial UEO

García, L. (2014). La teoría de la comunicación como matriz práctica para la resolución de conflictos. Comunicación y Sociedad, (23), 45-65. https://doi.org/10.32870/cys.v0i23.63 
Garvey, M. y Starr, B. (2019, 27 de septiembre). Estreno de 'Joker' genera precauciones de seguridad del Ejército de EE.UU. y Policía de Los Ángeles. CNN. https://cnnespanol.cnn.com/2019/09/27/ estreno-de-Joker-genera-precauciones-de-seguridad-del-ejercito-de-ee-uu-y-policiade-los-angeles/

González, R. y Orozco, G. (2012). Una coartada metodológica. Tintable.

Haskin, B. (1953). La Guerra de los mundos [película]. Paramount Pictures.

Hernández-Santaolalla, V. (2018). Los efectos de los medios de comunicación de masas. Universitat Oberta de Catalunya.

Hierro, L. (2018, 19 de noviembre). Armas en los institutos de Estados Unidos: 220 tiroteos en 18 años. El País. https://elpais.com/elpais/2018/11/06/planeta_futuro/1541528094_805836.html

Jensen, K. (2014). La comunicación y los medios: metodologías de investigación cualitativa y cuantitativa. Fondo de Cultura Económica.

Lasswell, H. (1927). Propaganda Technique in the World War. MIT Press.

Lasswell, H. (1948). The structure and function of communication in society. Recuperado de: http:// www.irfanerdogan.com/dergiweb2008/24/12.pdf

Lazarsfeld, P. y Merton, R. (1985). "Comunicación de masas, gustos populares y acción social organizada". En: M. de Moragas (ed.). Sociología de la comunicación de masas II. Estructura, funciones y efectos (pp. 22-49). Barcelona: Gustavo Gili.

Martín-Serrano, M. (2019). La comunicación y la información en un mundo que se virtualiza. Desarrollos y funciones previsibles. Comunicación y Sociedad, 1-29. https://doi.org/10.32870/ cys.v2019i0.7478

Meneses, M. y Pérez, G. (2016). Cómo y qué se estudia sobre Internet y la Sociedad de la Información en México. Una mirada desde la AMIC. Comunicación y Sociedad, (26), 43-70. https://doi.org/10.32870/cys.v0i26.1506

Nolan, C. (2012). The Dark Knight Rises [película]. Legendary Pictures

Phillips, T. (2019). Joker [película]. Warner Bross Pictures.

Pineda, A. (2007). Orígenes histórico-conceptuales de la teoría de la propaganda nazi. Historia y Comunicación Social, 12, 151-176. Recuperado a partir de https://revistas.ucm.es/index.php/ HICS/article/view/HICS0707110151A

Ramos, D. (2014). La prevalencia de los medios de comunicación o de la comunicación interpersonal como el futuro de la comunicación. Razón y Palabra, (88). https://www.redalyc. org/pdf/1995/199532731002.pdf

Requeijo, P., Sanz, C. y Del Valle, C. (2013). Propaganda norteamericana en la Primera Guerra Mundial: Simplificación y deformación a través del cartel. Historia y Comunicación Social, 18, 31-42. https://doi.org/10.5209/rev_HICS.2013.v18.43412

Román, M. (2002). Balance sobre la comunicación en la segunda mitad del siglo XX. Historia y Comunicación Social, (7), 201-216. https://revistas.ucm.es/index.php/HICS/article/view/ HICS0202110201A 
Rotten Tomatoes. (2019). Joker. Rotten Tomatoes. https://www.rottentomatoes.com/m/Joker_2019

Sosa, J. y Arcila, C. (2013). Manual de teoría de la comunicación: I. Primeras explicaciones. Universidad del Norte.

Soto, R., Meinardo, F., Fiotti, J. y Chausovsky, I. (2017). La viralización de la violencia: el rol de los medios de comunicación en la multiplicación de casos [ponencial. IX Congreso Internacional de Investigación y Práctica Profesional en Psicología XXIV Jornadas de Investigación XIII Encuentro de Investigadores en Psicología del Mercosur, Facultad de Psicología, Universidad de Buenos Aires, Argentina.

Vázquez, M. y Leetoy, S. (2016). Memoria histórica y propaganda. Una aproximación teórica al estudio comunicacional de la memoria. Comunicación Y Sociedad, (26), 71-94. https://doi. org/10.32870/cys.v0i26.5436

Vidales, C. (2014). Historia, teoría e investigación de la comunicación. Comunicación y Sociedad, (23), 11-43. https://doi.org/10.32870/cys.v0i23.60

Vidales, C. (2015). El relativismo teórico en comunicación. Entre la comunicación como principio explicativo y la comunicación como disciplina práctica. Comunicación y Sociedad, (16), 11-45. https://doi.org/10.32870/cys.v0i16.1102

Vidales, C. (2017). De la comunicación como campo a la comunicación como concepto transdisciplinar: historia, teoría y objetos de conocimiento. Comunicación y Sociedad, (30), 45-68. https://doi.org/10.32870/cys.v0i30.6840

Ximénez de Sandoval, P. (2019, 4 de octubre). El estreno de 'Joker' inquieta más allá de las salas de cine. El País. https://elpais.com/cultura/2019/10/03/actualidad/1570091845_470465.html 